Research Article

\title{
Estimation of Strong Wind Distribution on the Korean Peninsula for Various Recurrence Periods: Significance of Nontyphoon Conditions
}

\author{
Jae-Hee Hahm, ${ }^{1}$ Ha-Yoon Jeong, ${ }^{1}$ and Kyung-Hwan Kwak ${ }^{2}{ }^{2}$ \\ ${ }^{1}$ Department of Environmental Science, Kangwon National University, Chuncheon 24341, Republic of Korea \\ ${ }^{2}$ School of Natural Resources and Environmental Science, Kangwon National University, Chuncheon 24341, Republic of Korea \\ Correspondence should be addressed to Kyung-Hwan Kwak; khkwak@kangwon.ac.kr
}

Received 25 November 2018; Revised 21 March 2019; Accepted 26 March 2019; Published 14 April 2019

Academic Editor: Tomeu Rigo

Copyright (C) 2019 Jae-Hee Hahm et al. This is an open access article distributed under the Creative Commons Attribution License, which permits unrestricted use, distribution, and reproduction in any medium, provided the original work is properly cited.

\begin{abstract}
Long-term automated synoptic observing system (ASOS) data collected from 101 stations over a period of 50 years (1967-2016) were analyzed to investigate the distribution of strong winds on the Korean peninsula by utilizing a statistical method. The Gumbel distribution was used to estimate the wind speed for recurrence periods of 1, 10, 50, 75, and 100 years. For all recurrence periods, the coastal regions experienced higher wind speeds, which exceeded the strong wind advisory level, than the inland and metropolitan regions. The strong winds were predominantly induced by summertime typhoons, especially in the south and west coastal regions. In addition, nontyphoon factors, such as a topographical factor with atmospheric instability in a mountainous coastal region, can cause localized severe weather in the form of strong wind. By performing the weather research and forecasting (WRF) model simulation, an abrupt increase in wind speed up to $20 \mathrm{~m} \cdot \mathrm{s}^{-1}$ was reproduced under the condition of onshore prevailing winds heading toward a mountain ridge in a coastal region. Estimation of strong wind spatial distribution can help the region-to-region establishment of an action plan to prepare for damage caused by strong winds.
\end{abstract}

\section{Introduction}

Climate change is currently causing the strength and frequency of severe weather events such as typhoons, heat waves, and droughts to increase [1]. Typhoons are common severe weather events that mainly occur in the northwest region of the Pacific Ocean. Their strong winds and localized heavy rainfall cause a great deal of damage in Pacific coastal countries such as the Philippines and Taiwan, as well as in East Asian countries such as Japan, China, and South Korea [2]. The strong winds of typhoons can exert forces greater than the loads that are sustainable for roofs, windows, and signs in urban areas, thereby damaging manmade structures. Enormous societal costs, such as flight cancellations and delays in ship departures, are also incurred because of such storms [3].

The extent of damage due to strong winds is highly dependent on the position of the target relative to the path of the typhoon $[4,5]$. Homes and boats on the eastern side of the path of a typhoon tend to suffer more damage because of strong winds, whereas those on the western side experience more flood damage due to localized heavy rains [6]. In a previous study [7], typhoon simulations were used to estimate future severe wind speeds on the Korean peninsula. They projected that the wind speeds of storms occurring in the southern coastal region of the Korean peninsula, which is within the typical path of typhoons, will substantially increase in the future.

Many studies that estimate the current distribution of strong winds have been performed to procure wind power resources [8]. Wind power resources are known to be very useful under the condition that the wind continuously blows in one direction, and the main concern is the average wind speed rather than the maximum wind speed. On the other hand, in the field of meteorological weather disasters, the main concern regarding wind speed is record-breaking 
maximum wind speeds. These have low probability of occurrence but can cause large amounts of damage. Many researchers have mainly focused on the winds related to typhoons when estimating the record-breaking maximum wind speeds caused by strong winds [9-11]. However, there are more than a few cases of strong winds that are related to nontyphoon conditions, such as gusts caused by atmospheric instability or seasonal winter cold surges [12].

Well-known methods for estimating the wind-speed distribution probabilities according to the recurrence period are based on long-term weather observation data that have been analyzed by using statistical functions (i.e., Weibull and Gumbel distributions). In South Korea, the extreme wind speed was estimated by applying the Gumbel distribution to past weather observation data; the results were similar to the actual wind-speed observation data [13]. Given this, the purpose of this study was to analyze the spatial distribution of wind speed data for the last 50 years that are associated or not associated with a typhoon by applying the Gumbel distribution to estimate the maximum wind speed distribution for recurrence periods. By using the estimated results, we investigated the probability of strong winds to occur in the future and analyzed the unexpected strong winds that may occur under nontyphoon conditions by using a mesoscale meteorological model.

\section{Data and Methodology}

2.1. Observation Data. This study used automated synoptic observing system (ASOS) data from 101 locations over South Korea, as provided by the Korea Meteorological Administration (KMA) (Figure 1). The ASOS automatically measures the air temperature, relative humidity, wind speed, and wind direction near the ground every minute. We analyzed the daily maximum wind speed and daily maximum instantaneous wind speed data for the 50-year period (i.e., 1967-2016). The daily maximum instantaneous wind speed refers to the momentary and strongest wind speed measurement obtained during a single day (00-24h). The daily maximum wind speed refers to the highest average wind speed that was measured during a 10 -minute duration in a single day (00-24 h). The daily maximum instantaneous wind speed is related to damage within cities, such as the destruction of city structures. The term "strong winds" refers to the 10-minute-averaged wind speeds that are greater than $14 \mathrm{~m} \cdot \mathrm{s}^{-1}$, and the thresholds for strong wind advisories and alerts were defined by the Korea Ministry of Public Administration and Security as being greater than 14 and $21 \mathrm{~m} \cdot \mathrm{s}^{-1}$, respectively. In order to compare the regional characteristics on the Korean peninsula, in this study, all ASOS locations were classified as one of the following types: metropolitan (9 locations), central inland (22 locations), southern inland (31 locations), west coast (9 locations), south coast (21 locations), and east coast (9 locations) regions. The standard for delimiting the central inland and southern inland regions was their division at Chungcheongbuk-do Goesan-gun $\left(36^{\circ} 38^{\prime} \mathrm{N}, 127^{\circ} 51^{\prime} \mathrm{E}\right)$, and the standard for delimiting the coasts was a $10 \mathrm{~km}$ distance from the coastline [14]. The ASOS locations in large cities

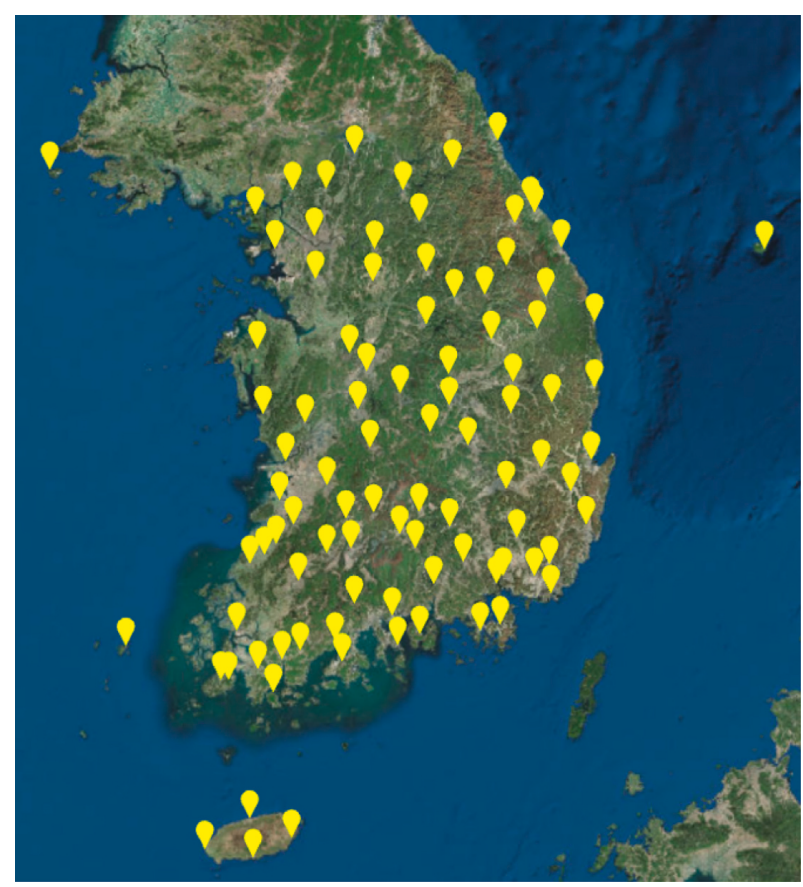

FIgURE 1: Distribution of ASOS locations over South Korea.

with a population of more than a million people were classified as metropolitan region. To distinguish the wind speed measurement for the nontyphoon condition, the periods within two days from the date that the corresponding ASOS was affected by a typhoon were designated as typhoon cases, in accordance with the Typhoon White Book published by the Korean Meteorological Administration [15].

2.2. Wind Speed Estimation. A Gumbel function is a probability density function that estimates a cumulative distribution under the condition that the mean and standard deviation of the full population is the same as the mean and standard deviation of the sample population if the number of samples is sufficiently large [16]. The characteristic values that determine the shape of the Gumbel distribution are $a$ (scale parameter) and $b$ (location parameter). The Gumbel distribution equations are as follows:

$$
\begin{aligned}
V(T) & =\frac{-1}{a} \ln \left[\ln \left(\frac{T}{T-1}\right)\right]+b, \\
a & =\frac{1}{0.78 \sigma}, \\
b & =\mu-0.45 \sigma,
\end{aligned}
$$

where $a$ and $b$ are calculated by using the sample mean value $(\mu)$ and standard deviation $(\sigma)$ and $V(T)$ is the expected recurrent wind speed for year $T$. Figure 2 shows the cumulative frequency results for the daily maximum instantaneous wind speed data from the Heuksando ASOS station; the profile is an example of Gumbel distribution. In 


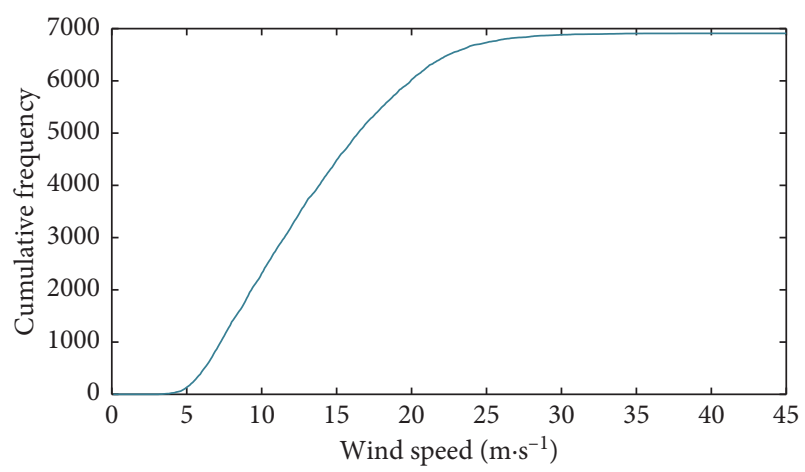

Figure 2: Example of cumulative frequency results for the daily maximum instantaneous wind speed data from the Heuksando ASOS station.

the example, $\mu$ is $13.3 \mathrm{~m} \cdot \mathrm{s}^{-1}$ and $\sigma$ is $5.5 \mathrm{~m} \cdot \mathrm{s}^{-1}$. In this study, $1,10,50,75$, and 100 years were, respectively, selected as the recurrence periods $(T)$ of the Gumbel distribution.

2.3. Spatial Distribution. Geographic information system (GIS) software (ArcGIS Pro, ESRI) was used to show the spatially interpolated distribution of the estimated wind speed data from each ASOS location for each recurrence period by using the Gumbel distribution. The locations of the ASOS stations in the used data did not cover all areas of the Korean peninsula, particularly near coastlines. To overcome this problem, we selected virtual points on the borders of the Korean peninsula and substituted the wind speeds at the corresponding locations with the wind speeds of the closest ASOS stations, following the same methodology of a previous study [17]. To check the validity of selected boundary points, the differences in daily maximum instantaneous wind speed between the ASOS location and the closest automatic weather station (AWS) were analyzed. Although the boundary points are located near coastlines, the reproduced wind speeds at the boundary points were reasonable when using the spatial interpolation method.

Table 1 shows the location information of the boundary points that approximately correspond to the selected ASOS location on the Korean peninsula. After adding the boundary points, the kriging interpolation method was applied to all ASOS stations and boundary points to spatially interpolate the wind speeds on the Korean peninsula. This process was performed by using administrative area information provided by the National Geographic Information Institute. In the interpolated wind speed distribution on the Korean peninsula and nearby seas, only the inland data were extracted and used in the analysis.

2.4. Mesoscale Meteorological Model. A numerical model that simulates a $3 \mathrm{D}$ meteorological field over a mesoscale domain was used to analyze the evolution and distribution of unexpected strong winds as a case study. The weather research and forecasting (WRF) model version 3.9.1 is a widely used numerical meteorological model for research and operational purposes $[18,19]$. Figure 3 shows the three
TABLE 1: Selection of boundary points.

\begin{tabular}{lcc}
\hline Boundary point & Location & ASOS \\
\hline Easternmost & East of Ulleung island & Ulleungdo \\
Southernmost & South of Jeju island & Seogwipo \\
Northernmost & North of Goseong & Sokcho \\
Westernmost & West of Baekryeongdo & Baekryeongdo \\
\hline
\end{tabular}

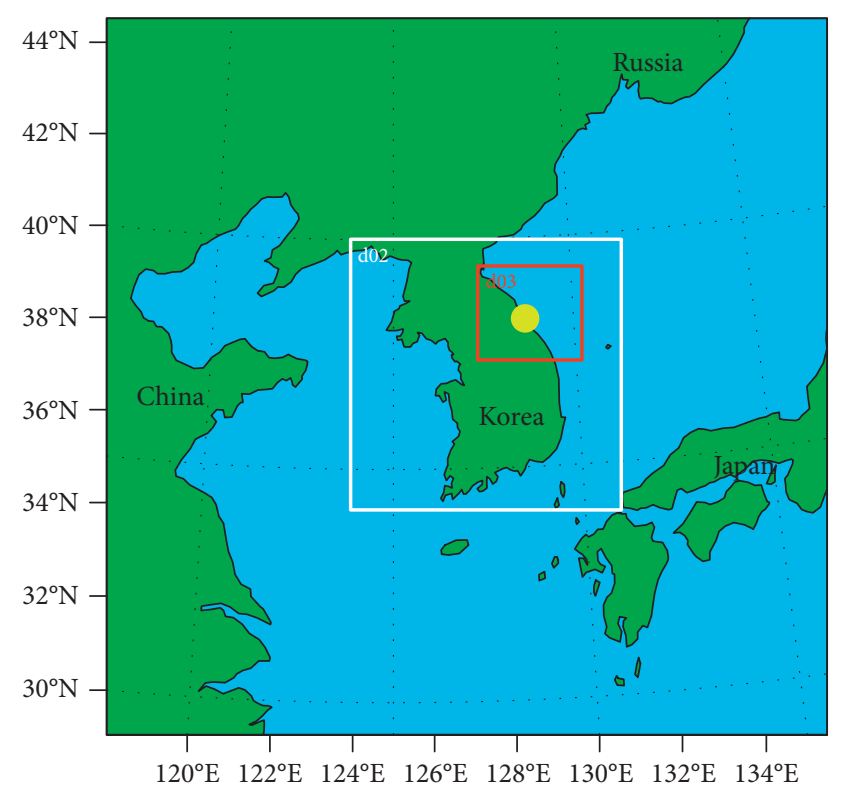

FIgURE 3: Nested WRF model domain over the Korean peninsula.

nested model domains with respective horizontal resolutions of 9, 3, and $1 \mathrm{~km}$ that are centered around the eastern coastal region of the Korean peninsula. As a nontyphoon condition, an unexpected strong wind event that occurred in the eastern coastal region during the period of October 2223,2006 , was selected for the simulation. The simulation was performed from 18 UTC on October 21 to 18 UTC on October 24, 2006, and the first $21 \mathrm{~h}$ were considered to be the spin-up time. NCEP final (FNL) reanalysis data with a $1^{\circ} \times 1^{\circ}$ grid resolution were used as the initial and boundary conditions of the simulation. An RRTM longwave physics scheme, a Goddard shortwave physics scheme, a Noah land surface model, and an MYJ PBL scheme were used in the simulation.

\section{Results and Discussion}

3.1. Observed Wind Speeds. To understand the 50-year period observation data, we analyze the historical records and frequency distributions of daily maximum instantaneous and daily maximum wind speeds by regions. Figure 4 shows a comparison of the maximum values for the daily maximum instantaneous wind speeds and daily maximum wind speeds in the six regions over the 50-year period of $1967-$ 2016. On average, the daily maximum instantaneous wind speed was approximately 1.5 times higher than the daily maximum wind speed, and this difference was the greatest in the eastern coastal region (1.8 times). By observing the data 


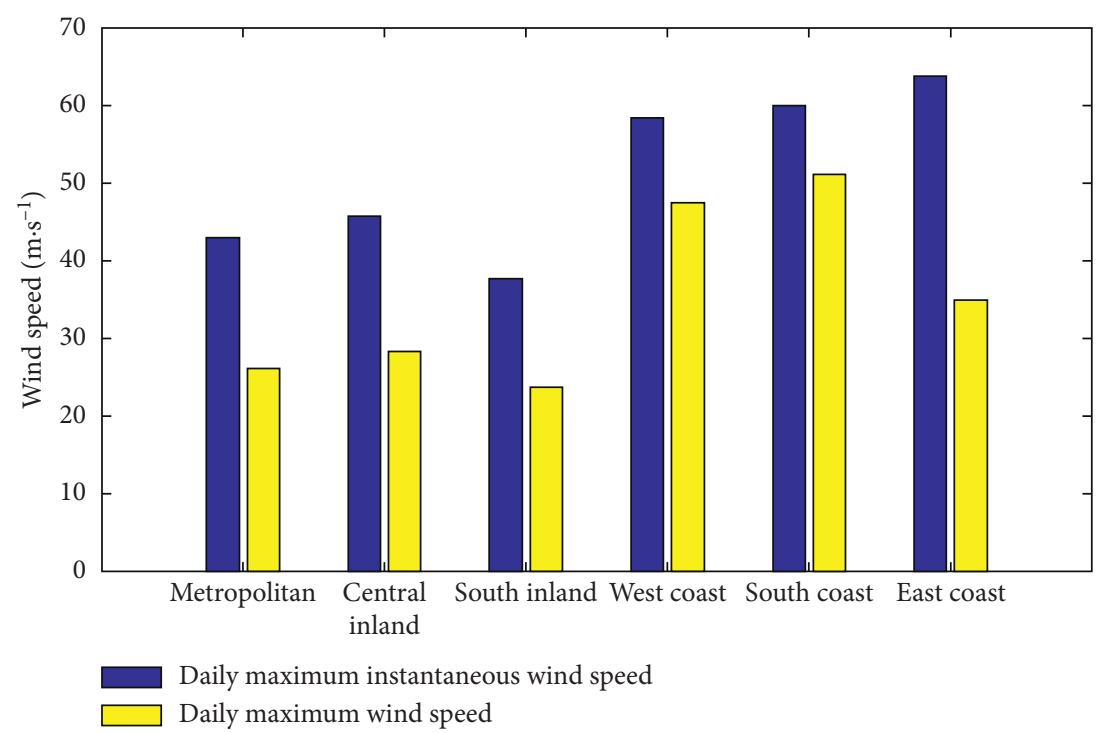

Figure 4: Comparisons of maximum values of the daily maximum instantaneous wind speed (dark blue) and daily maximum wind speed (yellow) in the six regions.

by region, it can be seen that the daily maximum instantaneous wind speed and daily maximum wind speed were higher in the coastal regions than in the metropolitan and inland regions. These results are consistent with the general trend reported in a previous study [20] in which wind speeds in the coastal regions over the Korean peninsula were higher and wind speeds in the inland regions were lower. The daily maximum instantaneous wind speed was the highest in the western coastal region $\left(63.7 \mathrm{~m} \cdot \mathrm{s}^{-1}\right)$ and the lowest in the southern inland region $\left(37.7 \mathrm{~m} \cdot \mathrm{s}^{-1}\right)$. It is believed that the phenomenon of the daily maximum instantaneous wind speed being higher in the eastern coastal region can be attributed to the topographical effect [21]. The northeastern air stream driven by low atmospheric pressure along with the cold air stream from the northern area of the East Sea strongly converged into the mountain ridge near the eastern coastal region. It is noteworthy that even though the daily maximum instantaneous wind speed of the southern inland region was relatively low $\left(37.7 \mathrm{~m} \cdot \mathrm{s}^{-1}\right)$, this wind speed is still above the strong wind warning level.

Figures 5 and 6 show the distributions of daily maximum instantaneous wind speed and daily maximum wind speed frequency in each region over the 50 -year period. The frequencies of the daily maximum instantaneous wind speed in the metropolitan and inland regions were the highest in the $5-7 \mathrm{~m} \cdot \mathrm{s}^{-1}$ range, whereas those in the coastal regions were the highest in the higher range (i.e., $7-9 \mathrm{~m} \cdot \mathrm{s}^{-1}$ ). The daily maximum instantaneous wind speed in the eastern coastal region results in the highest frequency just below the $10 \mathrm{~m} \cdot \mathrm{s}^{-1}$ range. In the eastern coastal region, in particular, topographically induced strong winds frequently occurred, not just owing to the summer typhoons and winter cold surge but also to the atmospheric instability that is typically observed in spring and autumn. Therefore, this region had a higher frequency of strong wind occurrence than other regions. We examined the mechanism of strong wind in the region due to the topographical effect by performing a numerical simulation in the separate subsection later. Similar to the aforementioned daily instantaneous maximum wind speed, the highest frequency of daily maximum wind speed range was at $5-6 \mathrm{~m} \cdot \mathrm{s}^{-1}$ in the eastern coastal region and near $3 \mathrm{~m} \cdot \mathrm{s}^{-1}$ in the other regions. Based on the 50 -year observation data, the frequencies of daily maximum instantaneous wind speeds that exceeded the strong wind advisory level were $12 \%, 18 \%, 17 \%$, and $22 \%$ in the metropolitan, western coastal, southern coastal, and eastern coastal regions, respectively, relative to the total number of days. In contrast, that in the inland regions was less than $1 \%$; thus, it is clear that the probability of strong winds occurring in the inland regions is relatively small. In addition, the frequencies of daily maximum wind speeds that exceeded the strong wind advisory level were not negligible relative to the total number of days, as they were $1 \%, 3 \%$, $2 \%$, and $2 \%$ in the metropolitan, western coastal, southern coastal, and eastern coastal regions, respectively.

3.2. Estimated Wind Speed Distribution for Various Recurrence Periods. Figure 7 shows the estimated wind speed distribution for each recurrence period based on the daily maximum wind speed observation using the Gumbel distribution. For the estimated wind speed distribution for a recurrence period of one year, wind speeds in the eastern coastal region were widely distributed in the range of $14-21 \mathrm{~m} \cdot \mathrm{s}^{-1}$. On the west coast and islands, there were locations where the daily maximum wind speed was consistently higher than $27 \mathrm{~m} \cdot \mathrm{s}^{-1}$. Most of the daily maximum wind speeds for a one-year period in the inland regions were lower than $14 \mathrm{~m} \cdot \mathrm{s}^{-1}$, implying that strong winds exceeding the strong wind advisory level occur approximately less than once a year in inland regions. In comparison, however, the 


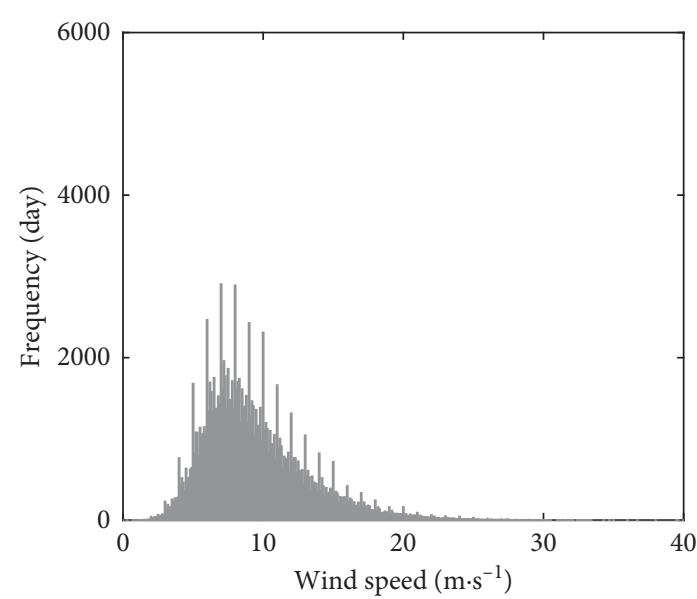

(a)

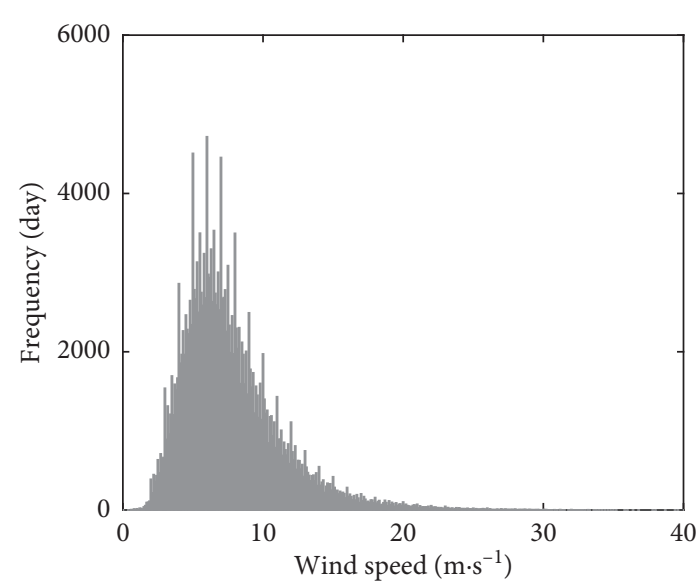

(c)

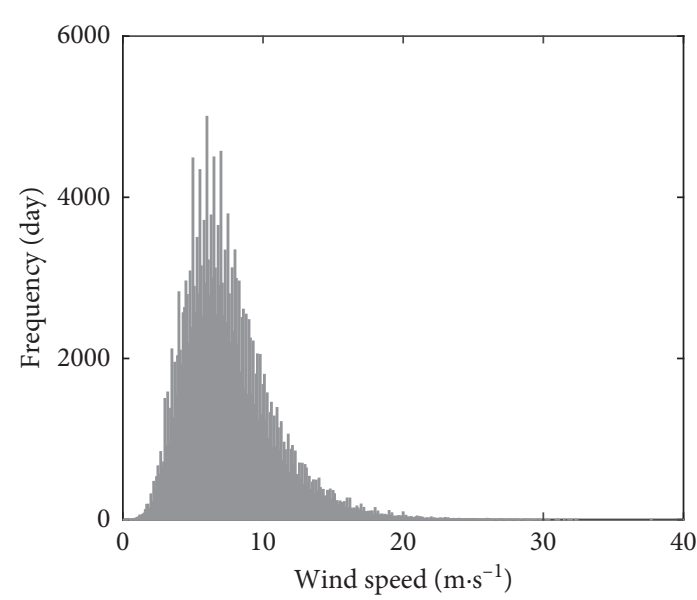

(e)

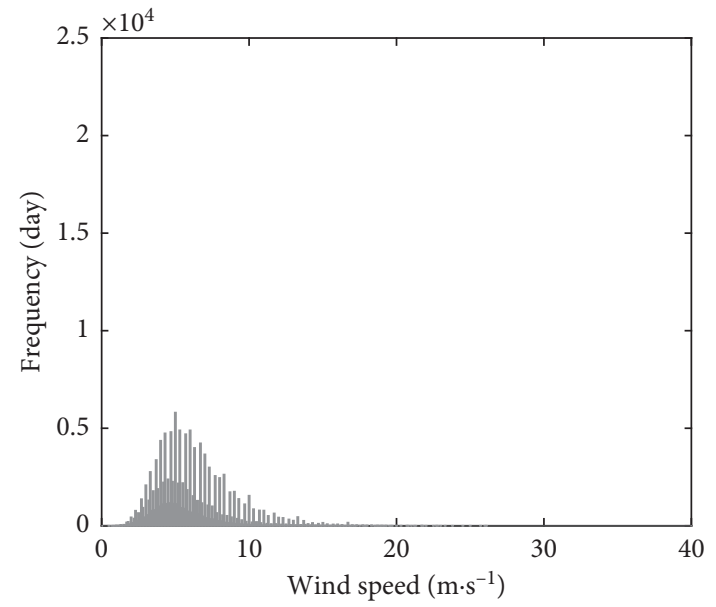

(b)

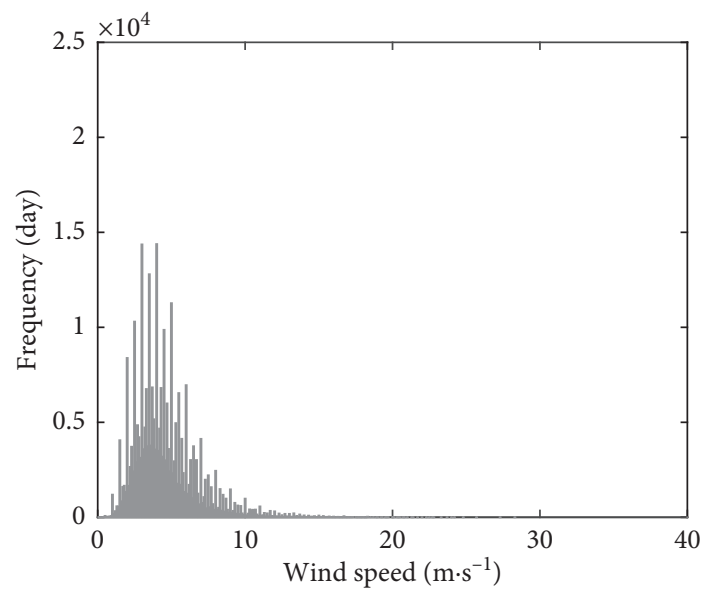

(d)

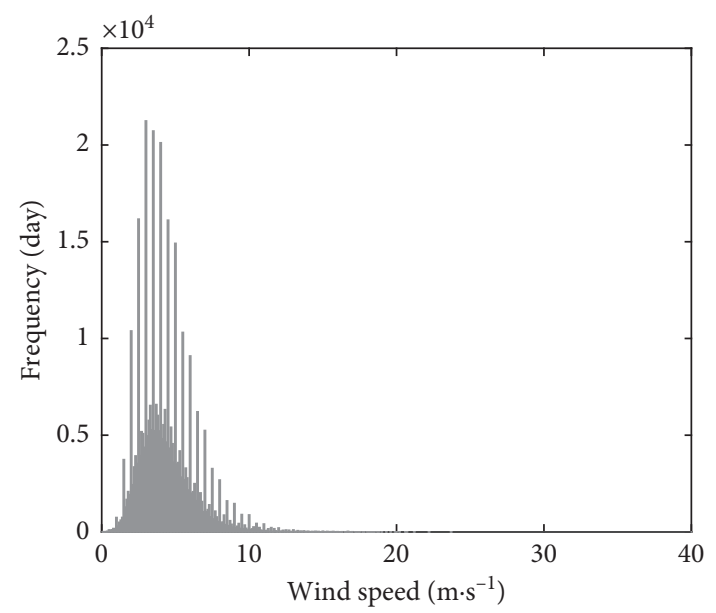

(f)

FIGURE 5: Daily maximum instantaneous wind speed (a, c,e) and daily maximum wind speed (b, d, f) frequencies in the metropolitan (top), central inland (middle), and south inland (bottom) regions.

estimated wind speed distribution for the recurrence period of 100 years shows that the daily maximum wind speed exceeded $21 \mathrm{~m} \cdot \mathrm{s}^{-1}$ in most of the coastal regions. In most areas of the Korean peninsula, there is a possibility that strong winds above $14 \mathrm{~m} \cdot \mathrm{s}^{-1}$ will occur at least more than once within a period of 50 or 100 years, as shown in the 50year observed wind speed records. While the damage caused by strong winds in the coastal regions is expected to be 


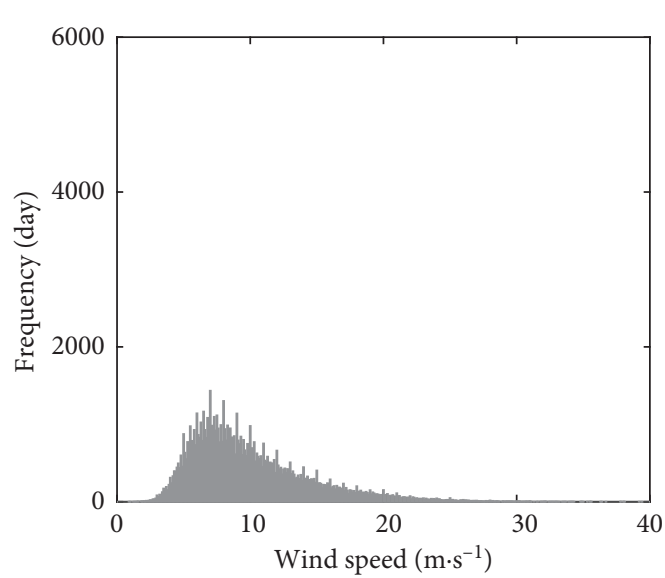

(a)

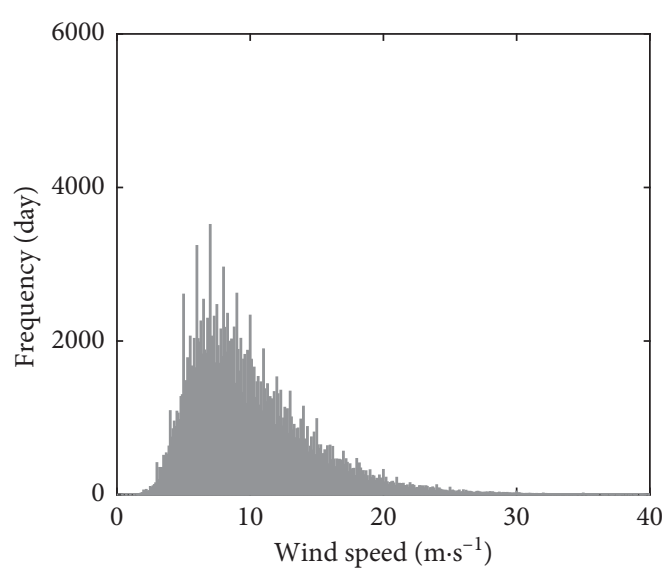

(c)

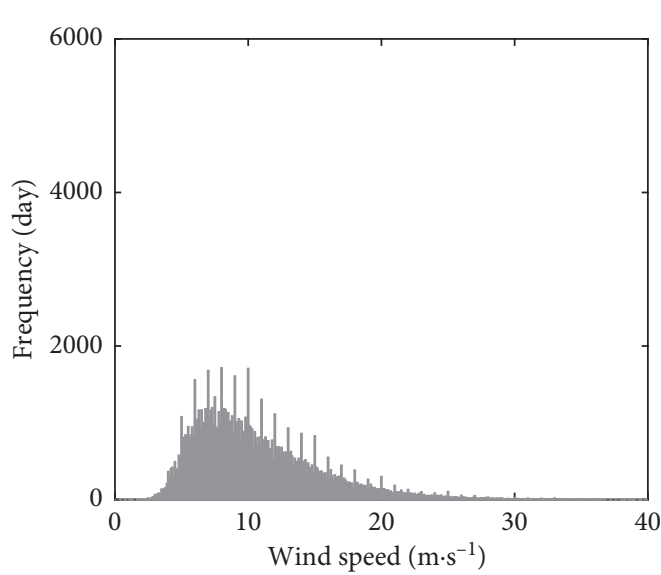

(e)

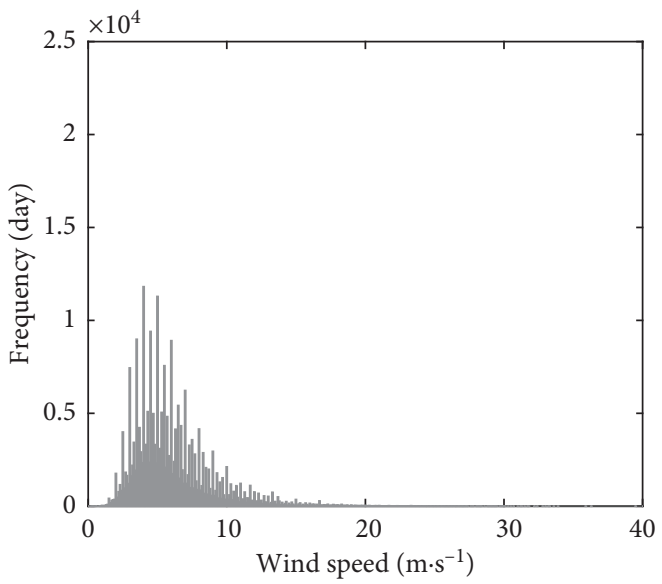

(b)

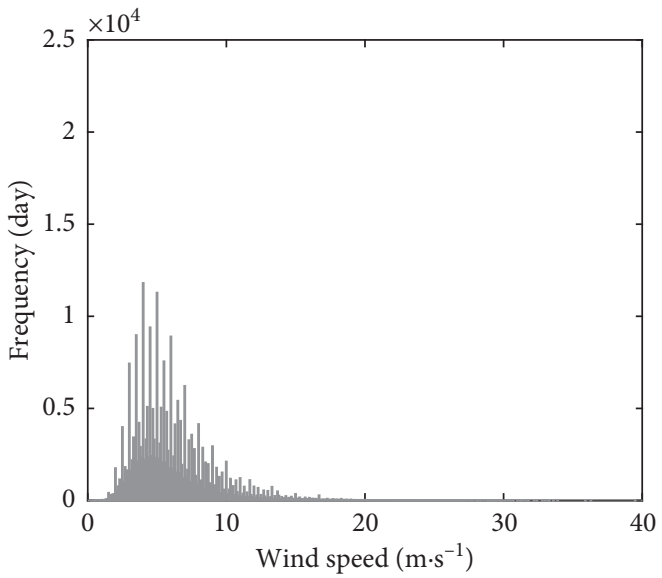

(d)

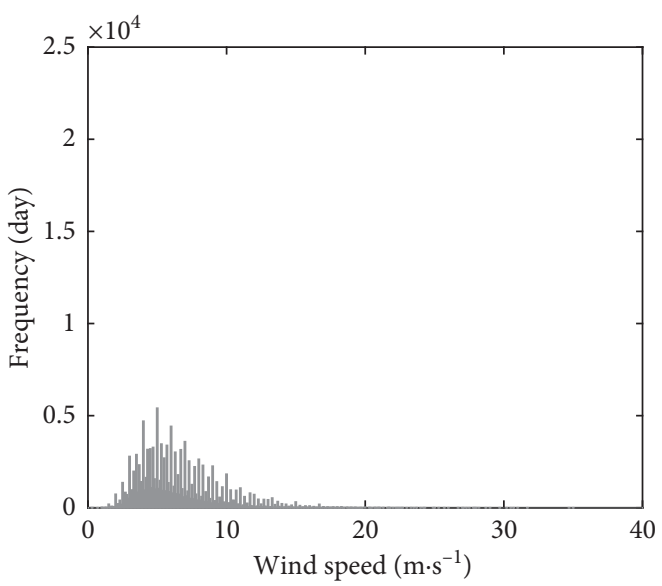

(f)

FIGURE 6: Daily maximum instantaneous wind speed ( $a, c, e)$ and daily maximum wind speed (b, d, f) frequencies in the western coastal (top), southern coastal (middle), and eastern coastal areas (bottom).

greater in terms of frequency and strength, these results also quantitatively show that the inland regions are also not safe from strong winds.

Table 2 shows the Gumbel distribution-based estimations of daily maximum wind speed for each recurrence period in each region. Six ASOS locations were selected to represent each corresponding type of region, including Busan for the metropolitan, Daegwallyeong for the central inland, Chupungryeong for the south inland, Heuksando for the west coast, Gosan for the south coast, and Ulleungdo for the east coast. A relatively strong wind with a daily maximum wind speed exceeding $14 \mathrm{~m} \cdot \mathrm{s}^{-1}$ for a recurrence period 


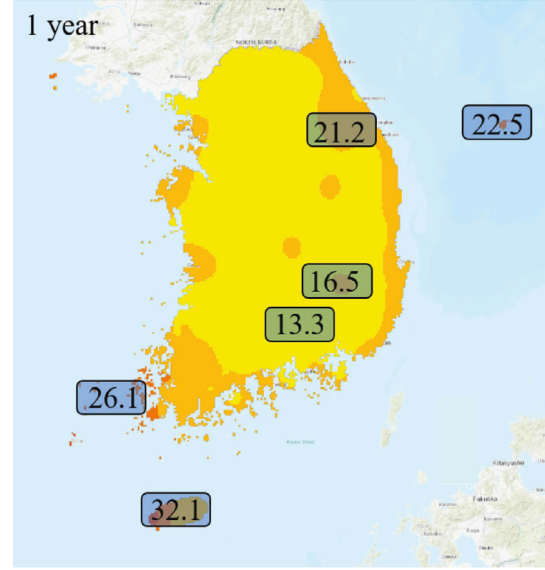

(a)

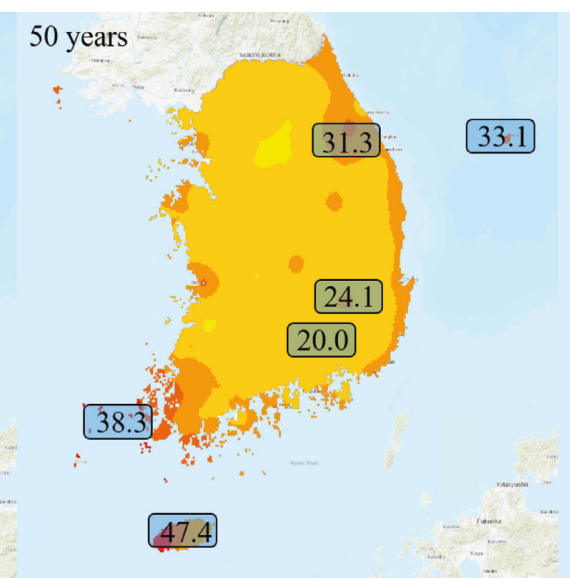

(b)

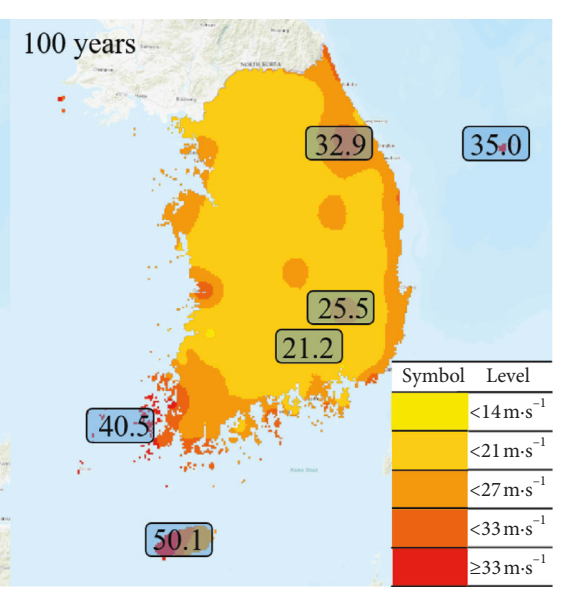

(c)

FIgURE 7: Gumbel distribution-based estimated distributions of daily maximum wind speeds for the recurrence periods of 1 year (a), 50 years (b), and 100 years (c).

TABLE 2: Gumbel distribution-based estimations of daily maximum wind speeds $\left(\mathrm{m} \cdot \mathrm{s}^{-1}\right)$ with recurrence periods of $1,10,50,75$, and 100 years.

\begin{tabular}{lccccc}
\hline \multirow{2}{*}{ Region } & Selected ASOS & \multicolumn{3}{c}{ Recurrence period (years) } \\
& & 1 & 10 & 50 & 75 \\
\hline Metropolitan & Busan & 20.5 & 25.9 & 29.7 & 30.6 \\
Central inland & Daegwallyeong & 21.2 & 27.1 & 31.3 & 31.3 \\
South inland & Chupungryeong & 17.0 & 21.6 & 24.8 & 32.4 \\
West coast & Heuksando & 26.1 & 33.3 & 38.3 & 25.6 \\
South coast & Gosan & 32.1 & 41.1 & 47.4 & 39.6 \\
East coast & Ulleungdo & 22.5 & 28.7 & 33.1 & 49.0 \\
\hline
\end{tabular}

of one year at all locations implies that strong wind can occur within a period of less than one year. In addition, the daily maximum wind speed for a 100-year recurrence period was $50.1 \mathrm{~m} \cdot \mathrm{s}^{-1}$ at the Gosan ASOS, which corresponds to the south coast region; this result is well supported by the fact that most of the record-breaking strong winds on the Korean peninsula during this 50-year period were observed at this location. The Gosan ASOS, where the estimated wind speed for all recurrence periods was the highest, is affected by the paths of typhoons and its geographical position as an island. Conversely, the Chupungryeong ASOS, where the wind speed was the lowest, is a location where the wind-reducing effects of complex topography can be clearly observed. According to the Beaufort wind force scale, a wind speed above $32.7 \mathrm{~m} \cdot \mathrm{s}^{-1}$ corresponds to strong wind enough to capsize a boat. For recurrence periods of 50 and 100 years, the daily maximum wind speeds exceeding this level were estimated for all coastal regions. A trend in which wind speeds increase at lower latitudes on the southwest coast of the Korean peninsula was reported in a previous study [22]; this trend is consistent with the results of this study. The conclusive results of daily maximum wind speed estimations for all areas of the Korean peninsula have shown that wind speeds were higher than $21 \mathrm{~m} \cdot \mathrm{s}^{-1}$, which is the wind speed that triggers strong wind warnings. It is necessary to make preparations to deal with strong winds and predict damage, particularly in regions with a high probability of strong wind damage.
To analyze the distribution of wind speed on the Korean peninsula only for the nontyphoon condition, we estimated the daily maximum wind speed by using the Gumbel distribution excluding the typhoon-effect days (Figure 8). As was earlier discussed, it was expected that the estimated wind speeds in the western and southern coastal regions would be significantly reduced for the nontyphoon condition. However, the daily maximum wind speeds estimated for the six ASOS locations maintained relatively high values even for the nontyphoon condition, particularly in the coastal regions. The most reduced wind speed was estimated at the Busan ASOS, which represents a metropolitan region, showing that the strong wind induced by a typhoon is the most significant factor in this type of region. This implies that factors other than the typhoon effect significantly affect the daily maximum wind speed for the analyzed recurrence periods. Considering these findings, we decided to focus on the topographical effect as one of the nontyphoon factors affecting strong wind generation under a nontyphoon condition.

3.3. A Case Study: Topographical Effect. To perform a numerical simulation focusing on the topographical effect in the east coast region using the WRF model, we selected the Daegwallyeong ASOS where the annual mean wind speed is climatologically the greatest over the Korean peninsula [23]. Figure 9 shows the observed and simulated wind speeds at the Daegwallyeong ASOS (indicated by a yellow dot in 


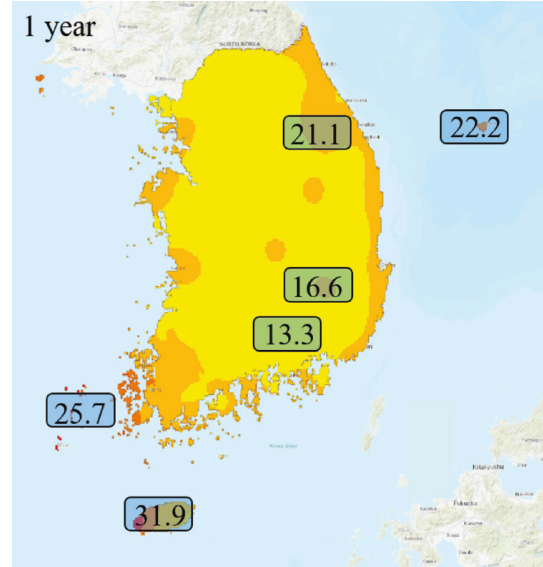

(a)

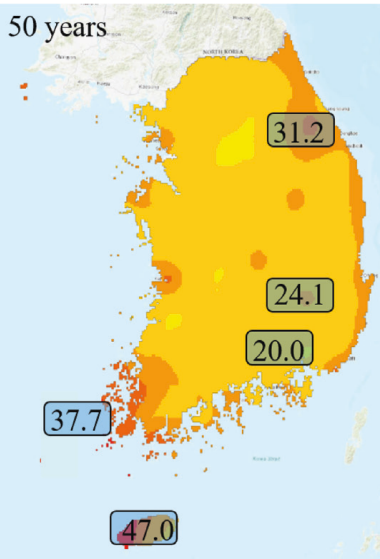

(b)

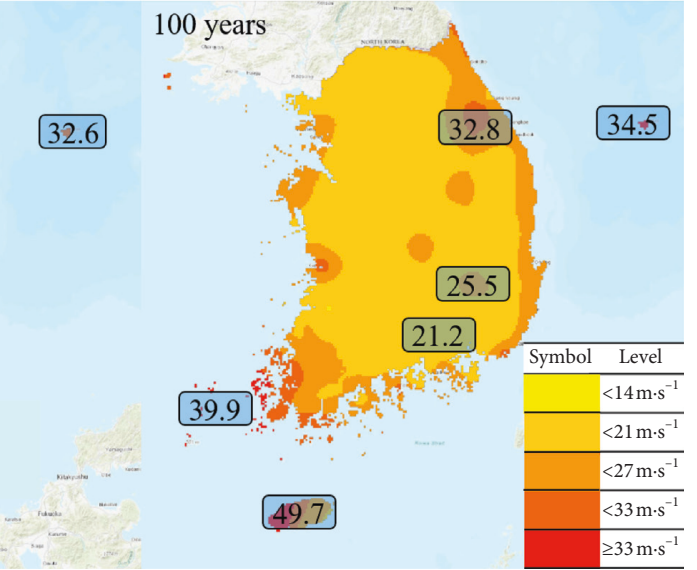

(c)

FIGURE 8: Gumbel distribution-based estimated distributions of daily maximum wind speeds occurring on the Korean peninsula excluding typhoon impacts for the recurrence periods of 1 year (a), 50 years (b), and 100 years (c).

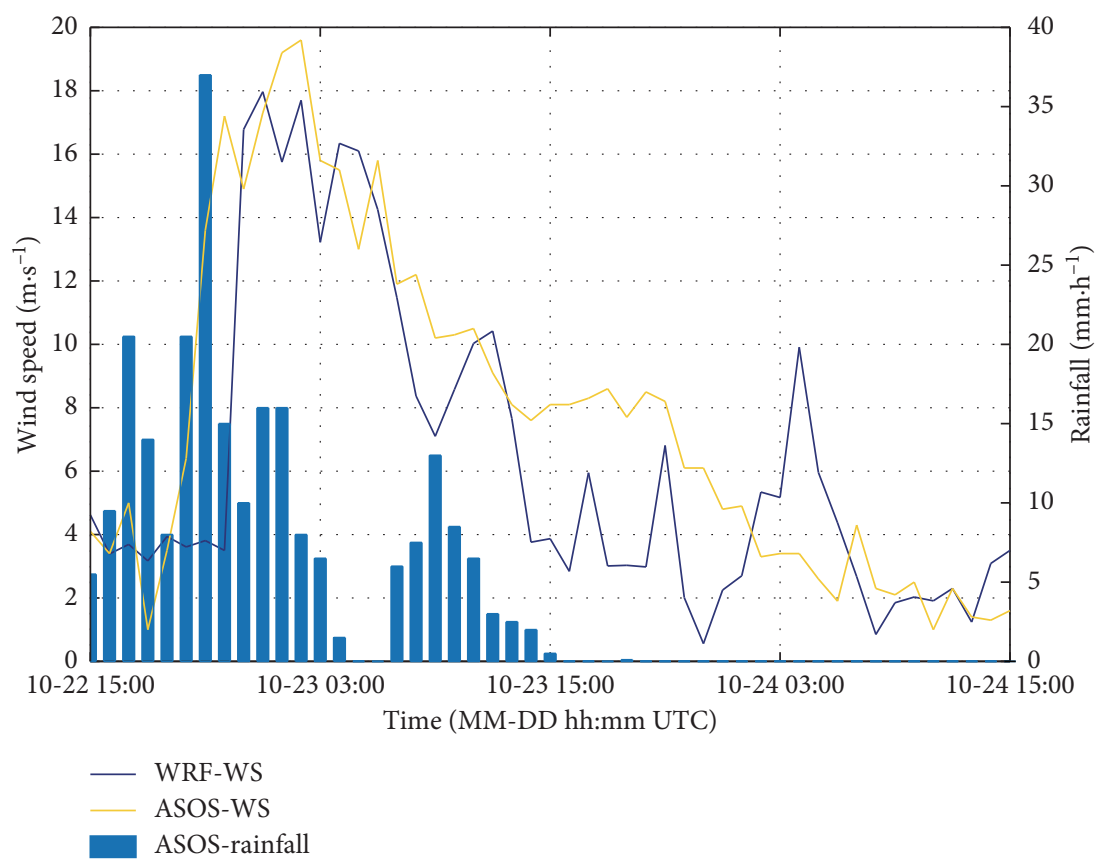

FIGURE 9: Time series of observed and simulated wind speeds and observed hourly rainfall amount at the Daegwallyeong ASOS from 15:00 UTC on October 22, 2006, to 15:00 UTC on October 24, 2006.

Figure 3) during a period that included an unexpected strong wind event in the mountainous region near the east coast of the Korean peninsula. This strong wind event was accompanied by a low-pressure-system passage with relatively heavy rain that resulted in a maximum hourly precipitation intensity of $38 \mathrm{~mm} \cdot \mathrm{h}^{-1}$. The WRF model well simulated the abrupt increase in wind speed up to approximately $20 \mathrm{~m} \cdot \mathrm{s}^{-1}$, with a $2 \mathrm{~h}$ delay on the night of October 22, 2006, that preceded a decreasing trend on October 23, 2006. This abrupt increase in wind speed was caused by atmospheric instability that was induced by the passage of a low-pressure system over the region.

Figure 10 shows the wind vector field in the WRF model domain and wind rose diagram that describes wind data at the Daegwallyeong ASOS during the strong wind event. In the presence of a low-pressure system to the south, the northeasterly wind was predominant in the coastal region and directly exerted a strong force onto the mountainous ridge, resulting in strong updraft and heavy rainfall. The wind rose diagram shows that the high wind speeds occurred in the northeastern direction, with a maximum wind speed that exceeded $15 \mathrm{~m} \cdot \mathrm{s}^{-1}$. This topographical effects near the eastern coastal region were mainly responsible for strong wind generation on the Korean peninsula except for the typhoon cases. Although typhoon-induced strong wind is still a major factor, the nontyphoon generation of strong wind was found to be comparable, especially in mountainous coastal regions. According to the KMA report [24], 


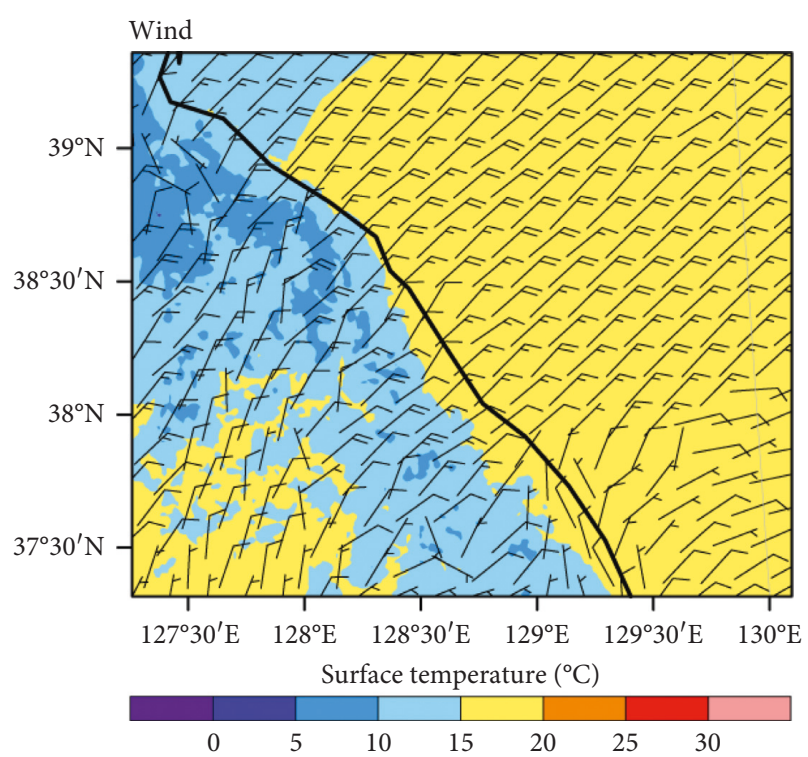

(a)

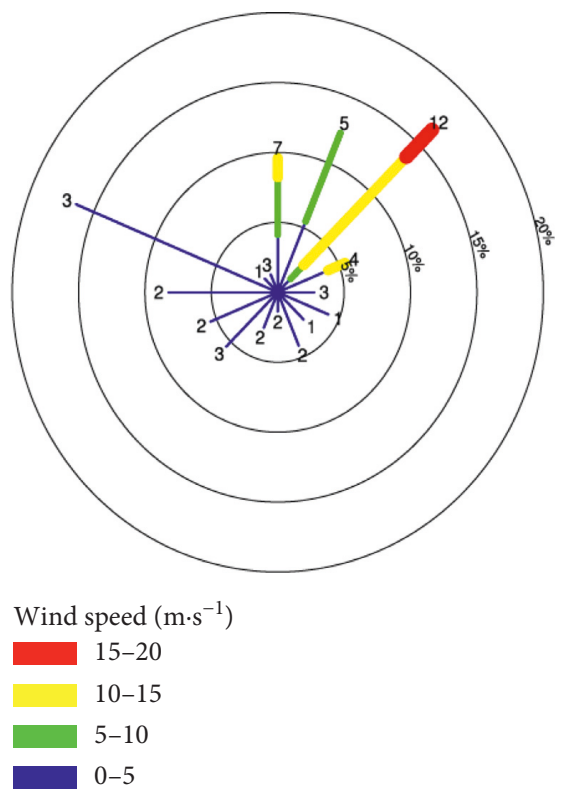

(b)

FIGURE 10: Simulated wind vector and surface temperature fields in the innermost WRF model domain at 24:00 UTC on October 22, 2006 (a), and wind rose diagram for the strong wind event observed at the Daegwallyeong ASOS (b).

strong winds in the mountainous region are generally attributed to steep air pressure gradient along the mountain slope. Other previous studies [25-27] also explained the role of steep mountainous slope in generation of strong wind in the Yeongdong region of Korea using the ARPS (Advanced Regional Prediction System) model simulation. As a result, the nontyphoon factors are also crucial for estimating the strong wind distribution on the Korean peninsula.

\section{Conclusions}

In this study, 50-year (1967-2016) ASOS observation data for the Korean peninsula were used to examine the strong wind distribution characteristics of the peninsula. The Gumbel distribution method was used to estimate wind speeds at each station for various recurrence periods. The results of estimated wind speed distributions in various regions showed that coastal regions were subjected to stronger winds than the inland and metropolitan regions and that the eastern and southern coastal regions were subjected to higher wind speeds than the western coastal region. Based on this, it was confirmed that the strong winds on the Korean peninsula that have occurred over the 50 -year period mainly occurred in the coastal regions, and also in mountainous regions that are subject to topographical effects. A considerable portion of these higher winds can be explained by typhoons. However, in some regions, it is believed that there are phenomena caused by the occurrence of localized strong winds. When the wind speed estimations for each recurrence period were performed by using the Gumbel distribution, stronger winds were estimated in the coastal regions than in the inland and metropolitan regions, with the exception of the central inland region. In the analysis of the strong wind that occurred under the nontyphoon condition, we clarified that the topographical effects can be comparable to the typhoon effect in terms of generating a localized strong wind event. Regarding the wind speed estimations that were based on daily maximum wind speed data, it was found that strong winds (above the level of strong wind advisory) could occur within a year in most areas of the Korean peninsula. Therefore, it was found that there is a need to prepare for strong winds, even in regions where strong winds occur relatively less frequently.

This study is significant, as it used past wind-speed observation data to determine the wind speed distribution on the Korean peninsula; these results were used to estimate the wind speeds for various recurrence periods. However, this study has the following limitation: wind speeds were not differentiated according to their cause when the data were analyzed. As climate change progresses and severe weather phenomena occur more frequently in East Asia, a clear distinction of the climatological factors that cause strong winds to occur should help establish detailed countermeasures according to the season, factor, and region.

\section{Data Availability}

The data used to support the findings of this study can be made available by the corresponding author upon request.

\section{Conflicts of Interest}

The authors declare that there are no conflicts of interest regarding the publication of this paper. 


\section{Acknowledgments}

This research was supported by a grant (2017-MOIS31-001) from the Fundamental Technology Development Program for Extreme Disaster Response funded by the Korean Ministry of Interior and Safety (MOIS).

\section{References}

[1] Ministry of the Interior and Safety, Statistical Yearbook of Natural Disaster, Ministry of the Interior and Safety, Seoul, South Korea, 2017.

[2] J.-W. Choi, Y. Cha, H.-D. Kim, and S.-D. Kang, "Climatological features of Korea-landfalling tropical cyclones," Advances in Meteorology, vol. 2016, Article ID 5051476, 15 pages, 2016.

[3] Ministry of the Interior and Safety, Disaster White Paper of 2002, Ministry of the Interior and Safety, Seoul, South Korea, 2008.

[4] J. K. Park, W. S. Jung, E. B. Kim, and J. S. Kim, "Characteristics of the state and distribution of damage by typhoon," Proceedings of Korean Society of Hazard Mitigation, p. 40, 2013.

[5] Y. Cha, J. Kim, K. Kang, N.-Y. Kang, and W.-T. Yun, "A study on the determination of Korea affecting tropical cyclone center for best tracking," Advances in Meteorology, vol. 2016, Article ID 5946342, 13 pages, 2016.

[6] S.-H. Ahn, B.-J. Kim, S.-L. Lee, and H.-K. Kim, "The characteristics of disaster by track of typhoon affecting the Korean Peninsula," Journal of the Korean Society of Hazard Mitigation, vol. 8, no. 3, pp. 29-36, 2008.

[7] S. Lee and G. Y. Kim, "Estimation of extreme wind speeds in Korean peninsula using typhoon Monte Carlo simulation," Journal of the Computational Structural Engineering Institute of Korea, vol. 29, no. 2, pp. 141-148, 2016.

[8] D. Carvalho, A. Rocha, M. Gómez-Gesteira, and C. Silva Santos, "WRF wind simulation and wind energy production estimates forced by different reanalyses: comparison with observed data for Portugal," Applied Energy, vol. 117, pp. 116-126, 2014.

[9] K. H. Lee and D. V. Rosowsky, "Synthetic hurricane wind speed records: development of a database for hazard analyses and risk studies," Natural Hazards Review, vol. 8, no. 2, pp. 23-34, 2007.

[10] J. H. Kwun, Y.-K. Kim, J.-W. Seo, J. H. Jeong, and S. H. You, "Sensitivity of MM5 and WRF mesoscale model predictions of surface winds in a typhoon to planetary boundary layer parameterizations," Natural Hazards, vol. 51, no. 1, pp. 63-77, 2009.

[11] K. W. Maw and J. Min, "Impacts of microphysics schemes and topography on the prediction of the heavy rainfall in Western Myanmar associated with tropical cyclone ROANU (2016)," Advances in Meteorology, vol. 2017, Article ID 3252503, 22 pages, 2017.

[12] S. G. Decker and D. A. Robinson, "Unexpected high winds in northern New Jersey: a downslope windstorm in modest topography," Weather and Forecasting, vol. 26, no. 6, pp. 902-921, 2011.

[13] B. H. Lee, B. J. Kim, D. W. Kim, H. G. Kim, and Y. C. Ha, “An estimation of extreme wind speeds using national wind map," Journal of the Wind Engineering Institute of Korea, vol. 14, no. 1, pp. 29-38, 2010.

[14] W. S. Cheong, J. H. Hwang, Y. S. Kang, and K. C. Na, "Study on the geographic and geologic centers in South Korea using
GIS," Journal of the Korean Earth Science Society, vol. 27, no. 4, pp. 416-424, 2006.

[15] Korean Meteorological Administration, Typhoon White Book, Korean Meteorological Administration, Seoul, South Korea, 2011.

[16] National Fire Agency, Development of the Assessment Technique to Wind and Snowfall Hazards, National Fire Agency, Sejong, South Korea, 2009.

[17] J.-J. Jeong and Y. Choi, "Study on interpolation methods to generate GIS-based climate maps," Journal of Climate Research, vol. 6, no. 1, pp. 159-170, 2011.

[18] W. C. Skamarock, J. B. Klemp, J. Dudhia et al., "A description of the advanced research WRF version 3," Tech. Rep. NCAR/ TN-475+STR, National Center for Atmospheric Research (NCAR), Boulder, CO, USA, 2008.

[19] K.-H. Kwak, J.-J. Baik, Y.-H. Ryu, and S.-H. Lee, "Urban air quality simulation in a high-rise building area using a CFD model coupled with mesoscale meteorological and chemistrytransport models," Atmospheric Environment, vol. 100, pp. 167-177, 2015

[20] Y.-K. Lee, S.-S. Lee, and H.-J. Ham, "A study on development and utilization of wind hazard maps," Journal of Korean Society of Hazard Mitigation, vol. 11, no. 3, pp. 1-8, 2011.

[21] J. S. Hong, "The impact assessment of high wind in the Youngdong region," Journal of Climate Research, vol. 2, no. 2, pp. 139-158, 2007.

[22] S.-D. Kwon and J.-H. Lee, "Estimation of extreme wind speeds in southern and western coasts by typhoon simulation," Journal of the Korean Society of Civil Engineers A, vol. 28, no. 4, pp. 431-438, 2008.

[23] J.-Y. Kim and D.-Y. Kim, "Spatio-temporal characteristics of wind observations over South Korea: 1982-2011," Asia-Pacific Journal of Atmospheric Sciences, vol. 49, no. 4, pp. 551-560, 2013.

[24] Korea Meteorological Administration, A Numerical Study of the Topographic Effect on the Downslope Wind and a Distribution of the Heavy Snowfall in the Yeongdong Area, Korea Meteorological Administration (KMA), Seoul, South Korea, 2012.

[25] J. G. Lee, "A numerical study of the orographic effect of the Taebak mountains on the increase of the downslope wind speed near Gangnung area," Journal of the Environmental Sciences, vol. 12, no. 12, pp. 1245-1254, 2003.

[26] W. Jang and H.-Y. Chun, "Severe downslope windstorms of gangneung in the springtime," Atmosphere, vol. 18, no. 3, pp. 207-224, 2008.

[27] W. Jang and H.-Y. Chun, "A numerical study on severe downslope windstorms occurred on 5 April 2005 at Gangneung and Yangyang, Korea," Asia-Pacific Journal of Atmospheric Sciences, vol. 46, no. 2, pp. 155-172, 2010. 

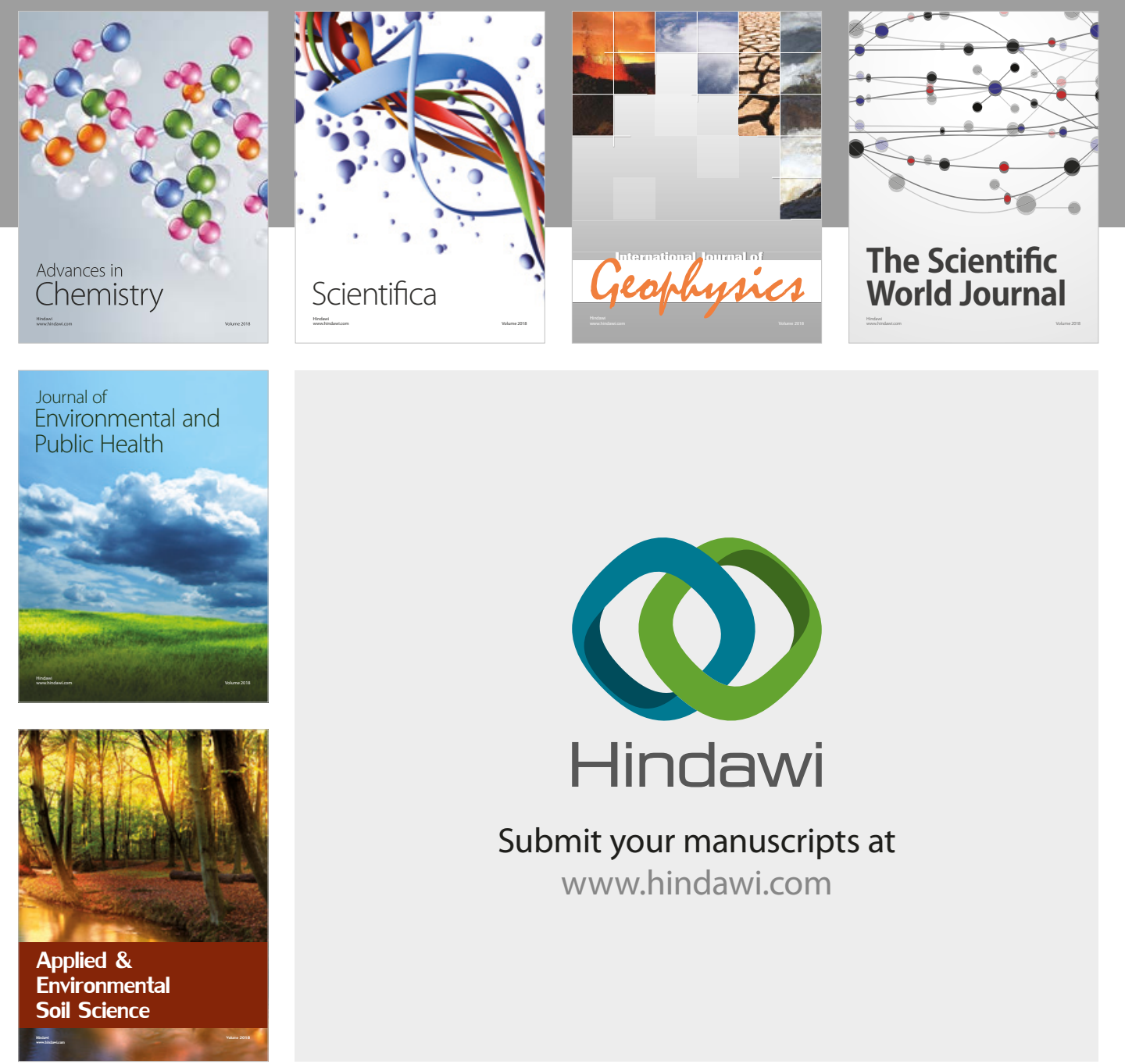

The Scientific

\section{World Journal}
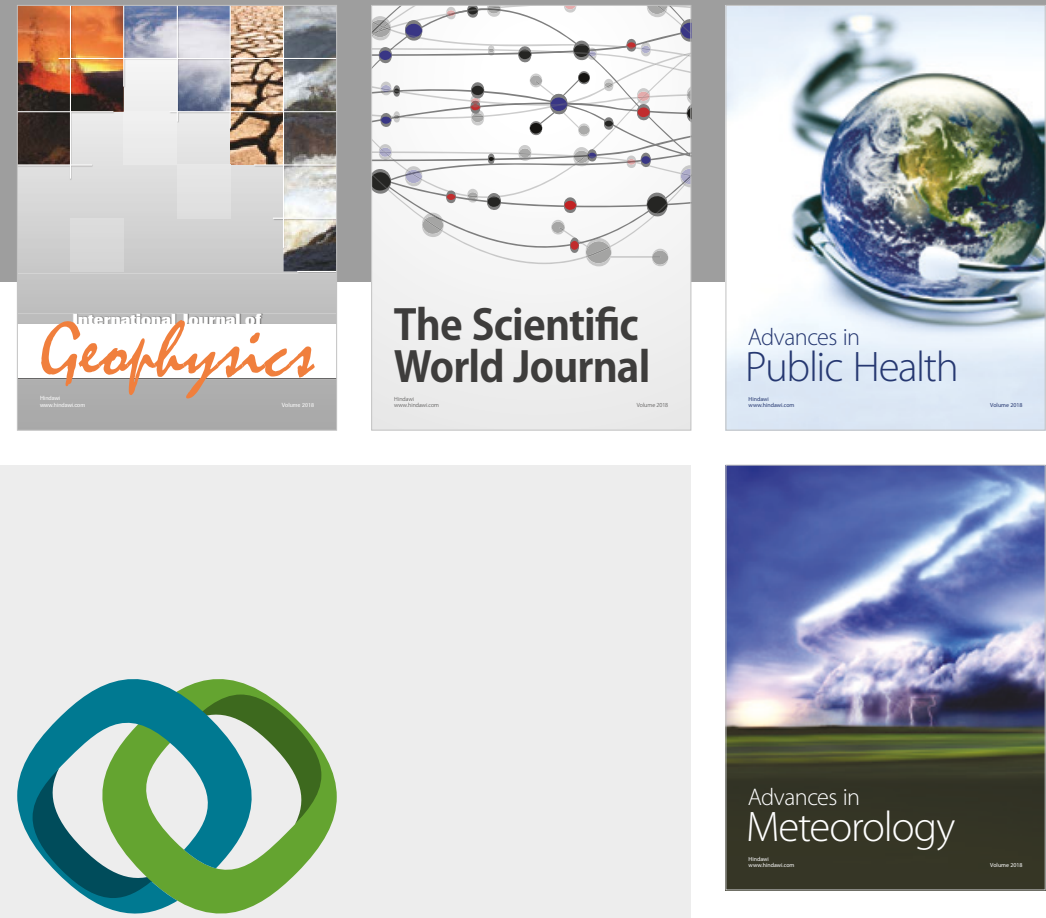

Advan

Public Health

\section{Hindawi}

Submit your manuscripts at

www.hindawi.com
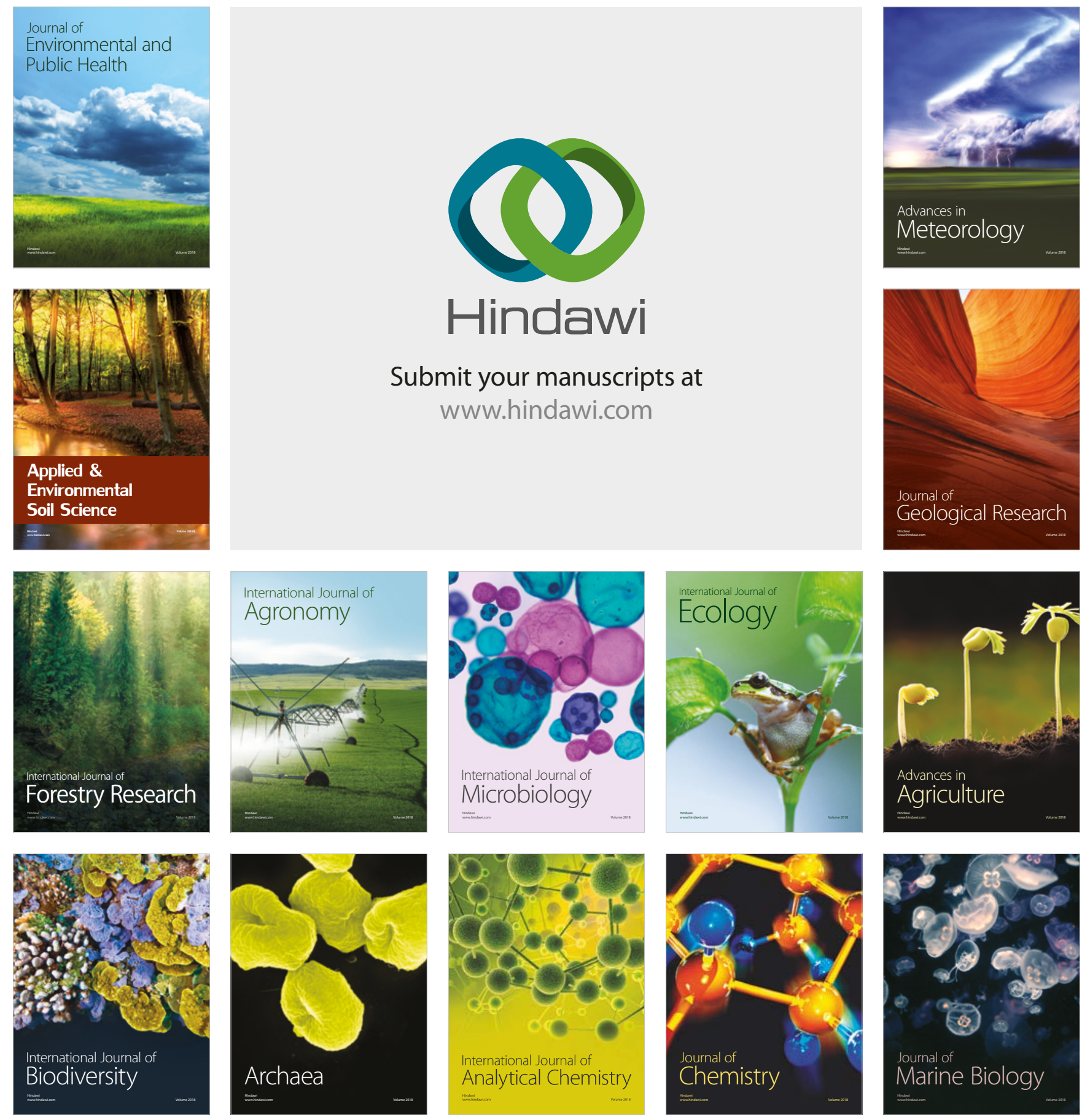